\title{
Cucumber mosaic virus 2b-Deficient Mutant Causes Limited, Asymptomatic Infection of Bell Pepper
}

Jongkit Masiri, Nubia V. Velasquez, and John F. Murphy, Department of Entomology and Plant Pathology, Auburn University, AL 36849

\begin{abstract}
Masiri, J., Velasquez, N. V., and Murphy, J. F. 2011. Cucumber mosaic virus 2b-deficient mutant causes limited, asymptomatic infection of bell pepper. Plant Dis. 95:331-336.

Cucumber mosaic virus Fast New York strain (CMV-Fny) containing a mutated $2 b$ protein $(C M V-F n y \Delta 2 b)$ was evaluated for the ability to infect 'Calwonder' bell pepper (Capsicum annuum) plants in comparative tests with the parent virus, CMV-Fny. Plants inoculated with CMV-Fny $\Delta 2 \mathrm{~b}$ did not develop local or systemic symptoms of infection, whereas CMV-Fny-infected plants developed systemic chlorosis by 7 days post inoculation (dpi), followed by mosaic and leaf deformation. Virus accumulation, determined by enzyme-linked immunosorbent assay (ELISA), revealed that CMV-Fny $\Delta 2 \mathrm{~b}$ accumulated in inoculated Calwonder leaves and inconsistently infected some noninoculated

leaves at a low titer but was not detected in the youngest, noninoculated leaves. Immuno-tissue blot tests did not detect CMV-Fny $\Delta 2 \mathrm{~b}$ in the stems of infected plants, whereas CMV-Fny accumulated throughout the length of the stems of inoculated plants. In two experiments, protoplasts were isolated from Calwonder leaves, inoculated with viral RNAs of CMV-Fny or CMV-Fny $\Delta 2 b$, and tested by ELISA for infection. In both experiments, less CMV-Fny $\Delta 2 \mathrm{~b}$ than CMV-Fny accumulated in protoplasts. These results suggest that the CMV $2 \mathrm{~b}$ protein is needed for systemic infection of Calwonder pepper plants and for accumulation of the virus in inoculated protoplasts.
\end{abstract}

Plant virus diseases cause considerable economic losses in crops worldwide. Vegetable crops are regularly threatened by viruses, although the prevalence and severity of virus outbreaks can vary from year to year (11). Plants infected by viruses show a reduction in plant growth and vigor, resulting in a decline in quality or market value of plant organs; in particular, fruit and seed (11). Cucumber mosaic virus (CMV; genus Cucumovirus, family Bromoviridae) is commonly identified among viruses infecting vegetable crops (31). CMV is recognized as a threat to a large variety of crops in tropical and temperate climates due, in part, to an extensive natural host range and the ability to be transmitted by more than 80 species of aphids in a nonpersistent manner $(8,12,22)$. As with most plant viruses, CMV-induced symptoms vary depending on host plant species and cultivar, virus strain, and environmental conditions. Perhaps most characteristic among the symptoms induced by CMV are foliar mosaic, leaf deformation (referred to as fern leaf, strap-leaf, or shoestring symptoms), and varying degrees of stunting $(18,23)$.

The potential ability of a plant to silence an invading virus using a sequence-specific targeting mechanism has been well documented $(6,15,16,26,32)$. Plant viruses are able to counteract the host plant gene-silencing mechanism by expression of suppressor proteins $(1,3,33)$. The Potato virus $Y$ HC-Pro protein and the CMV $2 \mathrm{~b}$ protein were among the first viral encoded gene-silencing suppressors identified $(1,3)$. Silencing CMV infection has immense practical value because this virus has the capability to induce severe losses in many crop plants (31). The Fast New York strain of CMV (CMV-Fny) typically induces severe symptoms in host plants, such as mosaic, deformation of leaves, and plant stunting $(18,22)$. A CMV-Fny isolate containing a mutated $2 b$ gene was able to infect Nicotiana tabacum, $N$. benthamiana, $N$. clevelandii, $N$. rustica, and Arabidopsis thaliana plants but, for each species, infected plants remained asymptomatic $(13,14,29,35)$. These findings

Corresponding author: J. F. Murphy, E-mail: murphjf@auburn.edu

Accepted for publication 22 November 2010.

doi:10.1094/PDIS-05-10-0392

(C) 2011 The American Phytopathological Society suggest that the CMV $2 \mathrm{~b}$ protein is an essential determinant for disease induction. Further investigations indicated that CMVinduced symptoms result from an interaction of the $2 \mathrm{~b}$ protein with other viral gene products $(4,34)$.

Cucumber mosaic, caused by CMV, is a persistent threat to bell pepper (Capsicum annuum L.) production worldwide (18). Asymptomatic infection of bell pepper plants by the CMV-Fny $2 \mathrm{~b}$ mutant, as observed in other plant species, may provide insight into novel management strategies for this virus. An asymptomatic infection without a corresponding reduction in virus titer, however, limits the practical value of this strategy (i.e., the infected plants may yield marketable fruit but also allow build up of virus inoculum within the crop). We evaluated the response of a CMV susceptible bell pepper cultivar, 'Calwonder', to inoculation with CMV-Fny (the wild-type parent isolate) and a CMV-Fny $2 \mathrm{~b}$ mutant. The results indicate that CMV-Fny $2 b$ is needed for systemic infection of Calwonder plants.

\section{Materials and Methods}

Viruses. Plasmids containing cDNAs to CMV RNA of each strain, CMV-Fny parent strain and CMV-Fny $\Delta 2 \mathrm{~b}$, were kindly provided by Dr. J. P. Carr (University of Cambridge, Cambridge). The plasmids were designated pFny109, pFny209, pFny309, and pFny209/M3, and encoded CMV-Fny RNA 1, RNA 2, RNA 3, and RNA $\Delta 2$ b, respectively. CMV-Fny RNA $\Delta 2$ b had a 294-bp deletion in the $3^{\prime}$ end of the RNA spanning nucleotides 2,419 to 2,713 $(27,29)$. Escherichia coli cultures containing each of the respective plasmids were maintained on Luria-Bertani agar medium containing ampicillin at $50 \mu \mathrm{g} / \mathrm{ml}$ and 5-bromo-4-chloro-3-indolyl- $\beta$-Dgalactopyranoside (x-gal) at $40 \mu \mathrm{g} / \mathrm{ml}$ (28). Plasmids were extracted from $E$. coli cultures using a Qiagen Miniprep kit (Qiagen Inc., Valencia, CA). Plasmid DNA $(1 \mu \mathrm{g} / \mu \mathrm{l})$ was linearized by treatment with Pst I (Invitrogen, Carlsbad, CA), then treated with Klenow DNA polymerase I (Promega Corp., Madison, WI) and transcribed in vitro using a T7 mMessage mMachine Kit (Ambion Inc., Austin, TX) according to the manufacturer's instructions. The resulting virus RNA transcripts were quantified using a NanoDrop 1000 Spectrophotometer (Wilmington, DE) and analyzed by agarose gel electrophoresis.

Plant growth conditions. All whole-plant experiments were performed in a greenhouse at the Plant Science Research Facility at 
Auburn University (Alabama) with average temperatures of $24 \pm$ 4.5 and $20 \pm 3.5^{\circ} \mathrm{C}$ by day and night, respectively. Pepper, tobacco, and squash seed were sown in 72-well Styrofoam trays (Speedling, Inc., Bushnell, FL) in Pro-Mix, a soilless potting medium (Premier Peat, Riviere-du-Loup, Quebec, Canada). Upon germination, seedlings were transplanted (one plant/pot) to 3.8-liter pots containing Pro-Mix supplemented with the controlled-release fertilizer Osmocote Classic 18-6-12 (Scotts Company LLC, Marysville, OH).

Inoculation procedures. The first experiments evaluated the response of pepper, squash, and tobacco plants to inoculation with CMV-Fny and CMV-Fny $\Delta 2 \mathrm{~b}$. Tobacco was considered a control treatment because it had been evaluated in previous studies $(29,30)$. In these experiments, the virus inoculum consisted of newly generated, in vitro-transcribed CMV RNAs. This experiment was performed twice, with each experiment carried out in a similar manner. In each experiment, virus inoculum was applied to three plants (= three replications) of each plant species (i.e., pepper, squash, and tobacco). For each experiment, equal quantities (1.0 $\mu \mathrm{g}$ ) of each CMV RNA were combined as RNAs 1, 2, and 3 for CMV-Fny and RNAs $1,2(\Delta 2 b)$, and 3 for CMV-Fny $\Delta 2 b$. Each RNA combination was mixed with RNA inoculation buffer $(1 \%$ [wt/vol] Celite, $37 \mathrm{mM} \mathrm{Na}_{4} \mathrm{P}_{2} \mathrm{O}_{7}$, and $1 \mathrm{mM}$ EDTA [pH 9.0]) and rub inoculated onto plants. Sets of transcripts representing each virus were inoculated onto Calwonder bell pepper, 'Dixie' zucchini squash (Cucurbita pepo L.), and 'Kentucky 14' tobacco ( $N$. tabacum L.). Virus was rub inoculated onto the first pair of true leaves of pepper plants when the plants were at the five- to sixtrue-leaf stage, onto each cotyledon of the squash plants when the first true leaf was 1 to $2 \mathrm{~cm}$ long, and onto the first pair of true leaves of tobacco plants when each leaf was 3 to $4 \mathrm{~cm}$ long. All plants were placed in the dark for $24 \mathrm{~h}$ prior to inoculation and maintained after inoculation at the Plant Science Research Facility greenhouse complex at Auburn University.

All subsequent experiments involved evaluation of Calwonder pepper plants only, in an effort to provide a more detailed analysis of CMV-Fny $\Delta 2 \mathrm{~b}$ infection of pepper. In each experiment, CMVFny and CMV-Fny $\Delta 2 \mathrm{~b}$ inocula consisted of systemically infected Kentucky 14 tobacco leaf tissue ground in $50 \mathrm{mM}$ potassium phos- phate buffer, $\mathrm{pH} 7.3$, containing $10 \mathrm{mM}$ sodium sulfite. Infected tobacco was used as inoculum rather than in vitro-transcribed RNAs because the size of the experiments (i.e., the number of plants to be inoculated) was much larger and required large amounts of inoculum. For the control treatment, plants were inoculated with buffer alone. Because CMV-Fny $\Delta 2$ b-infected Kentucky 14 plants were asymptomatic (see Results), the leaves were always tested by enzyme-linked immunosorbent assay (ELISA) prior to use as inoculum to confirm an adequate titer of the virus for inoculation. ELISA absorbance values were used to produce comparable amounts of virus for inocula (e.g., if the CMV-Fny titer was twice that of CMV-Fny $\Delta 2 \mathrm{~b}$, the amount of tissue used for CMVFny was half the amount used for CMV-Fny $\Delta 2 \mathrm{~b}$ ). These viruses have the same coat protein sequence and, therefore, reacted similarly to the commercial ELISA kit (see below).

For the experiments focusing on Calwonder pepper plants, each virus was rub inoculated onto the first and second leaves of plants at the five- to six-true-leaf stage. This experiment was performed twice, each in a randomized complete block design consisting of three blocks (replications) with 10 plants per virus treatment per block (30 plants in total for each virus treatment and 9 plants for the buffer-inoculated control treatment). Plant growth stages at inoculation and symptom evaluation were assessed as described previously (2). Briefly, leaves emerged in pairs on opposite sides of the stem, with the oldest leaf designated as leaf 1 and the oldest pair of leaves designated as leaves 1 and 2 .

Disease assessment and virus detection. In each experiment, plants were monitored for the number of days post inoculation for symptom appearance, and symptom severity at each rating. Virus accumulation was determined in inoculated and noninoculated leaves using a commercial CMV-specific ELISA kit (Agdia, Inc., Elkhart, IN) following the procedure recommended by the manufacturer. Each leaf sample was ground in general extraction buffer at a 1:5 ratio (grams of tissue/milliliters of buffer; buffer details provided by the manufacturer) using a motorized leaf-squeezing apparatus (Piedmont Machine and Tool, Six Mile, SC). Sap extracts were added to ELISA microtiter plates at a final dilution of 1 $\mathrm{g}$ of tissue $/ 20 \mathrm{ml}$ of buffer. During the steps for primary antibody

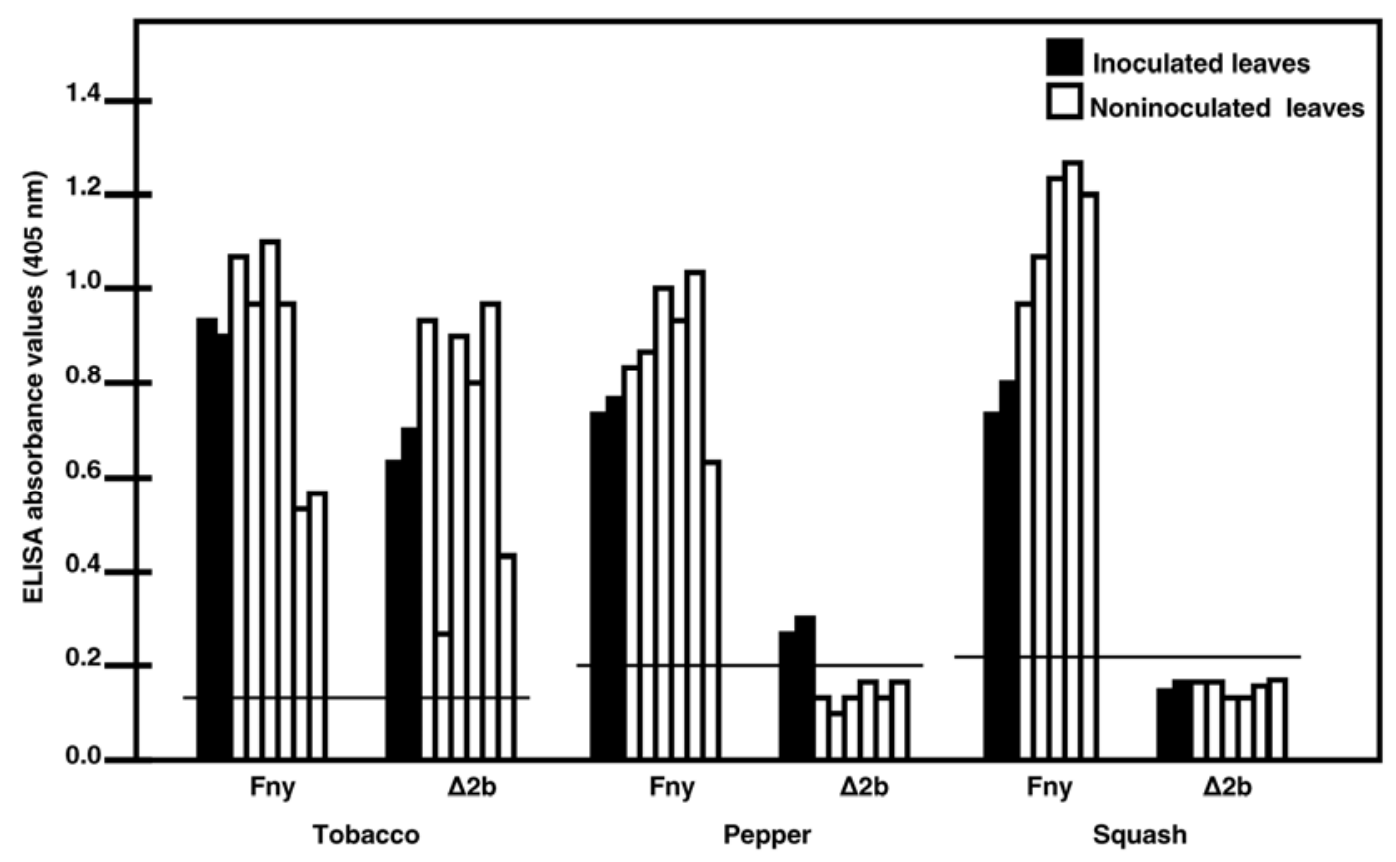

Fig. 1. Detection of Cucumber mosaic virus Fast New York strain (CMV-Fny) and CMV-Fny $\Delta 2 \mathrm{~b}$ ( $2 \mathrm{~b}$ mutant) in two oldest, inoculated leaves (black bars) and five or six younger, noninoculated leaves (white bars, oldest leaf to youngest leaf, left to right) of tobacco, pepper, and squash plants. Plants were inoculated with in vitro-generated transcripts of each virus. For each plant species, leaf samples were collected from each of three replicate plants/treatment 21 days post inoculation. Virus titers were determined by enzyme-linked immunosorbent assay (ELISA). Each bar, therefore, represents the average ELISA value for three replicate leaves each from a different plant. The horizontal line across each set of bars is the ELISA threshold based on the negative control plants; bars taller than the threshold line are considered positive for CMV detection. Results for the repeat of this experiment were almost identical (data not shown). 
coating and sap extraction, the plates were incubated in a moist chamber at $4^{\circ} \mathrm{C}$ for at least $12 \mathrm{~h}$ for each step. During the conjugated-antibody step, the plates were incubated in a moist chamber for 2 to $3 \mathrm{~h}$ at $37^{\circ} \mathrm{C}$. Substrate reactions (para-nitrophenylphosphate at $1.0 \mathrm{mg} / \mathrm{ml}$ [Sigma-Aldrich, St. Louis] in $10 \%$ diethanolamine, $\mathrm{pH} 9.8$ ) occurred at room temperature for 30 to $60 \mathrm{~min}$. A Sunrise microtiter plate reader (Phoenix Research Product, Hayward, CA) was used to record the absorbance values at $405 \mathrm{~nm}$. Samples were considered positive for the presence of CMV when the ELISA absorbance value was greater than the mean plus three standard deviations of the absorbance value for three to five comparable healthy control samples in each microtiter plate.

In experiments involving inoculation of freshly generated viral RNA transcripts onto pepper, squash, and tobacco plants, the inoculated plants were sampled 21 days post inoculation (dpi) (Fig. 1). For these experiments, inoculated leaves 1 and 2 were tested individually for each pepper and tobacco plant, as were the inoculated cotyledons for each squash plant. To determine whether the virus infection was systemic, the youngest six noninoculated leaves were tested individually for the virus in each plant species. The same protocol was used for the repeat experiment.

In experiments involving inoculation of Calwonder pepper plants only, using CMV-Fny- or CMV-Fny $\Delta 2 \mathrm{~b}$-infected tobacco tissue as inoculum, leaf sample collection differed for CMV-Fnyinoculated plants versus CMV-Fny $\Delta 2 b$-inoculated plants. For CMV-Fny-infected plants, systemic infection was apparent by the development of distinct symptoms of cucumber mosaic; therefore, only two noninoculated leaves were tested by ELISA. For CMVFny $\Delta 2$ b-inoculated plants, symptoms were not observed; therefore, five to six noninoculated leaves were tested. For each virus treatment, leaf samples were collected three times from plants, when the CMV-Fny-infected plants expressed each of three phases of symptom development as described previously (19): chlorosis (7 dpi), mosaic (12 dpi), and leaf deformation (approximately $25 \mathrm{dpi}$ ). Inoculated leaves 1 and 2 of plants infected with CMV-Fny were tested by ELISA along with the two youngest, noninoculated leaves. For CMV-Fny $\Delta 2$ b-inoculated plants, inoculated leaves 1 and 2 were tested along with the six youngest, noninoculated leaves, with the exception of the repeat experiment, in which a single inoculated leaf was tested at the mosaic (12 dpi) and leafdeformation ( $25 \mathrm{dpi}$ ) phases, and only four noninoculated leaves were tested at the mosaic phase (Fig. 2B).

The plants used for ELISA detection of viruses in leaves were also used to evaluate virus accumulation in the stems by immunotissue blot analysis $(2,10)$. In all, $1 \mathrm{CMV}$-Fny-inoculated plant, 10 CMV-Fny $\Delta 2$ b-inoculated plants, and 1 buffer-inoculated control plant were tested at each of three sampling periods based on occurrence of chlorosis, mosaic, and leaf deformation phases on CMVFny infected plants (19). A single plant was tested for the CMVFny-inoculated and buffer control treatments because results from these treatments were highly consistent and represented positive and negative control treatments, respectively. Positions along the stem selected for generating tissue prints included the internode immediately below the inoculated leaves and each internode above the inoculated leaves. Tissue prints were dried at room temperature and stored at $4^{\circ} \mathrm{C}$ until tested by serological analysis.

CMV detection in tissue prints was carried out as described by Guerini and Murphy (10). Membranes were incubated in 5\% powdered milk dissolved in Tris-buffered saline (TBS; $50 \mathrm{mM}$ Tris$\mathrm{HCl}$ at $\mathrm{pH} 7.4$ and $200 \mathrm{mM} \mathrm{NaCl}$ ) at room temperature for $1 \mathrm{~h}$ with gentle shaking (approximately $15 \mathrm{rpm}$ ). Blocked membranes were incubated in anti-CMV immunoglobulin (Ig) at $1.0 \mu \mathrm{g} / \mathrm{ml}$ in TBS at room temperature for at least $12 \mathrm{~h}$, then treated with TBS-powdered milk containing goat anti-rabbit Ig conjugated to alkaline phosphatase (Sigma-Aldrich) diluted 1:5,000, for $3 \mathrm{~h}$ in the dark at room temperature. Substrate $(50 \mathrm{mg}$ of nitroblue tetrazolium dissolved in $1 \mathrm{ml}$ of $70 \% \mathrm{~N}, \mathrm{~N}$-dimethyl formamide [Fisher Scientific Co., Fair Lawn, NJ], $5 \mathrm{mg}$ of 5-bromo-4-chloro-3-indolylphosphate [Sigma-Aldrich] dissolved in $1 \mathrm{ml}$ of $N, N$-dimethyl formamide, as well as $3 \mathrm{ml}$ of alkaline phosphatase buffer [1.0 M Tris-
$\mathrm{HCl}$, pH 9.5, $1.0 \mathrm{M} \mathrm{NaCl}$, and $\left.50 \mathrm{mM} \mathrm{MgCl}_{2}\right]$ ) were added to the membranes. Antibody-antigen reactions were developed at room temperature for $30 \mathrm{~min}$ and then stopped by rinsing the membranes with cold water.

Protoplast isolation and inoculation. Calwonder leaf protoplasts were isolated as described by Murphy and Kyle (20), and modified by Guerini and Murphy (10). Plants were grown in magenta boxes ( $77 \mathrm{~mm}$ wide by $77 \mathrm{~mm}$ long by $97 \mathrm{~mm}$ tall; SigmaAldrich) in a temperature-controlled chamber at $25^{\circ} \mathrm{C}$ under 12,000 lux illumination for $16 \mathrm{~h}$ of light and $8 \mathrm{~h}$ of darkness per day. Protoplasts generated from these plants were washed and concentrated by three cycles of centrifugation at $294 \times g$ at room temperature, and maintained in $0.42 \mathrm{M}$ mannitol as osmoticum. Protoplast numbers were determined with a hematocytometer by light microscopy at $\times 20$ magnification.

CMV-Fny and CMV-Fny $\Delta 2 \mathrm{~b}$ were each propagated in $N$. $t a-$ bacum Kentucky 14 and purified according to Palukaitis and Zaitlin (24). Viral RNAs were isolated from each purified virus preparation by several cycles of phenol:chloroform extraction (1:1:0.5 [vol/vol/vol/] virus/phenol/chloroform) followed by ethanol precipitation. Viral RNA concentrations were determined using a Nanodrop 1000 spectrophotometer.

Calwonder protoplasts were inoculated with either CMV-Fny RNA or CMV-Fny $\Delta 2$ b RNA by electroporation using a Gene Pulser Xcell Electroporation System (Bio-Rad Laboratories, Inc., Hercules, CA). For each virus, $0.5 \times 10^{6}$ protoplasts were inoculated with $20 \mu \mathrm{g}$ of viral RNA $(1 \mu \mathrm{g} / \mu \mathrm{l})$ using two 5-ms pulses of $150 \mathrm{~V}$. The inoculated protoplasts were placed on ice for $15 \mathrm{~min}$,

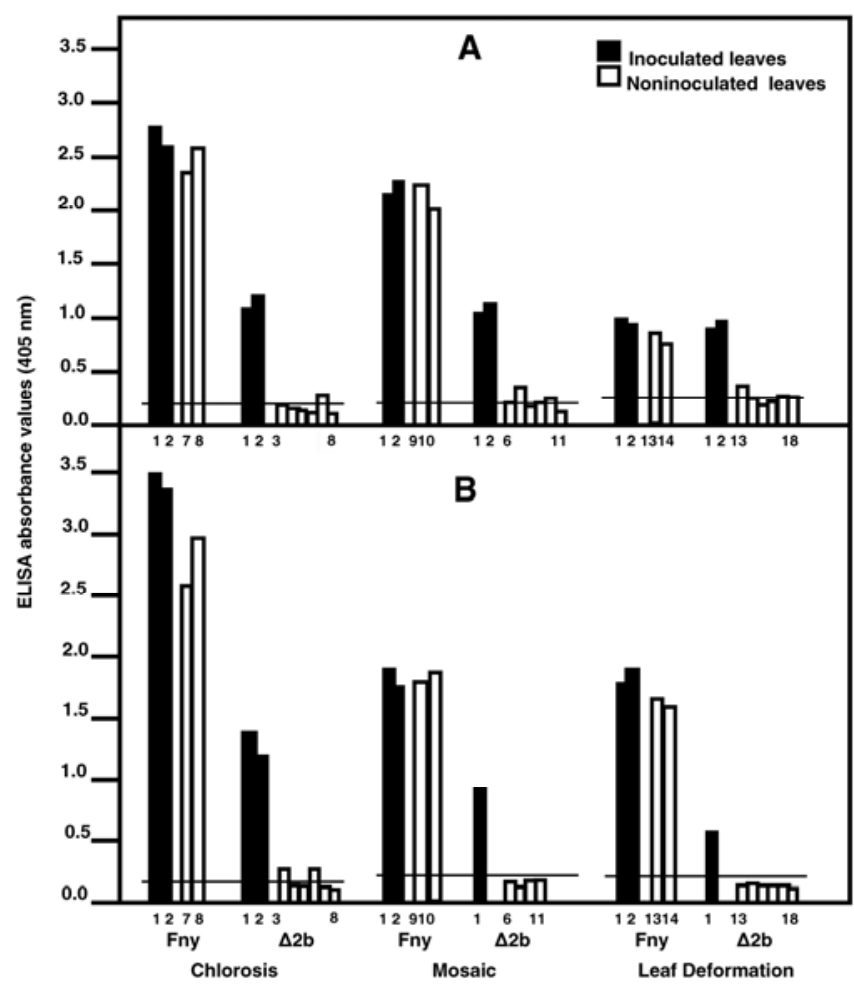

Fig. 2. Detection of Cucumber mosaic virus Fast New York strain (CMV-Fny) and $\mathrm{CMV}-\mathrm{Fny} \Delta 2 \mathrm{~b}$ ( $2 \mathrm{~b}$ mutant) in inoculated and noninoculated leaves of 'Calwonder' pepper plants. The experiment was carried out twice; $\mathbf{A}$, experiment 1 data and $\mathbf{B}$, experiment 2 data. Leaf samples were collected when CMV-Fny-infected plants expressed chlorosis (7 days post inoculation [dpi]), mosaic (12 dpi), and leaf deformation ( $25 \mathrm{dpi})$. Virus titers were determined by enzyme-linked immunosorbent assay (ELISA). Black bars represent average ELISA values for inoculated leaves and white bars represent average ELISA values for noninoculated leaves (older leaf to younger leaf, left to right) for eight individual plants. The number below each bar indicates the leaf that was tested (e.g., for CMV-Fny $\Delta 2$ b-inoculated plants at the chlorosis phase, leaves 1 and 2 were tested along with leaves 3 to 8 ). The horizontal line across each set of bars is the ELISA threshold based on leaves sampled from noninfected control plants; bars taller than the threshold line are positive for CMV detection. 
centrifuged at approximately $218 \times g$ for $2 \mathrm{~min}$, and resuspended in incubation medium containing $0.2 \mathrm{mM} \mathrm{KH}_{2} \mathrm{PO}_{4}, 1.0 \mathrm{mM} \mathrm{KNO}_{3}$, $0.1 \mathrm{mM} \mathrm{MgSO}_{4}, 0.1 \mathrm{mM} \mathrm{CaCl}_{2}, 1.0 \mu \mathrm{M} \mathrm{KI}$, and $0.01 \mu \mathrm{M} \mathrm{CuSO}_{4}$ (20). An antibiotic mix containing carbenicillin, cephaloridine, and nystatin (Sigma-Aldrich) was added at final concentrations of 100 , 100 , and $4 \mu \mathrm{g} / \mathrm{ml}$, respectively. Protoplasts were maintained in a growth chamber at $25^{\circ} \mathrm{C}$ with a photoperiod of $16 \mathrm{~h}$ of light and 8 $\mathrm{h}$ of darkness for $24 \mathrm{~h}$ post inoculation, at which time the protoplasts were counted and samples of $0.05 \times 10^{6}, 0.1 \times 10^{6}$, and $0.2 \times$ $10^{6}$ protoplasts were collected and tested for infection by the appropriate CMV strain using a CMV ELISA, as described above. This experiment was performed two times with the same procedure used each time.

\section{Results}

CMV inoculation of pepper, squash, and tobacco. None of the pepper, squash, or tobacco plants inoculated with CMV-Fny $\Delta 2 \mathrm{~b}$ developed symptoms of cucumber mosaic (data not shown). However, ELISA tests for CMV-Fny $\Delta 2 \mathrm{~b}$ accumulation in CMVFny $\Delta 2$ b-inoculated leaves and younger, noninoculated leaves of the same plants revealed different degrees of infection (Fig 1). Tobacco plants had relatively high CMV-Fny $\Delta 2 \mathrm{~b}$ titers in inoculated leaves and in all of the noninoculated leaves tested whereas, in pepper plants, CMV-Fny $\Delta 2 \mathrm{~b}$ was detected in inoculated leaves but not in any of the noninoculated leaves. CMV-Fny $\Delta 2 \mathrm{~b}$ was not detected in cotyledons or leaves of inoculated squash plants. In contrast, CMVFny induced characteristic symptoms of CMV infection on each of the plant species (data not shown). This included mosaic, deformation of leaves, and stunting of squash and tobacco plants. Pepper plants developed systemic chlorosis by $7 \mathrm{dpi}$, mosaic symptoms by $12 \mathrm{dpi}$, and leaf deformation by approximately $25 \mathrm{dpi}$, as described previously (19). Consistent with symptom expression, CMV-Fny accumulated to relatively high titers in both inoculated and noninoculated leaves of tobacco, pepper, and squash plants (Fig. 1). The repeat experiment showed very similar results for both virus strains in each of the plant species tested (data not shown).

Detailed evaluation of CMV-inoculated pepper plants. CMVFny $\Delta 2 \mathrm{~b}$ was detected by ELISA in inoculated leaf 1 (and leaf 2, when tested) during each of the three phases of symptom development associated with CMV-Fny infection (Fig. 2A and B). CMVFny $\Delta 2 \mathrm{~b}$ also was detected in a few noninoculated leaves tested at each of the three symptom phases in the first experiment (Fig. 2A) but only at the chlorosis phase $(7 \mathrm{dpi})$ in the second experiment
(Fig. 2B). There was no consistency among replicate plants and between the repeats of this experiment regarding which noninoculated leaves tested positive for CMV-Fny $\Delta 2 \mathrm{~b}$. In experiment 1 , CMV-Fny $\Delta 2 \mathrm{~b}$ was detected only in one of eight leaf samples, representing leaf 7 of the six noninoculated leaves tested at the chlorosis phase; two of eight replicate leaves representing leaf 7 and one of eight replicate leaves representing leaf 10 at the mosaic phase; and two of eight replicate leaves representing leaf 13 of the six noninoculated leaf samples at the leaf deformation phase (Fig. $2 \mathrm{~A})$. In the repeat experiment (experiment 2), one of eight replicate leaves contained detectable CMV-Fny $\Delta 2 \mathrm{~b}$ for each of noninoculated leaves 3 and 6 but none of the noninoculated leaves tested at the mosaic and leaf deformation phases was positive for CMVFny $\Delta 2 b$ (Fig. 2B).

In addition, leaf samples collected from plants with each virus treatment and then analyzed by reverse-transcription polymerase chain reaction (RT-PCR) assay confirmed the presence of only the CMV strain inoculated onto the plants (data not shown). Overall, CMV-Fny $\Delta 2 \mathrm{~b}$ detection was primarily limited to inoculated leaves, with inconsistent detection in noninoculated leaves; the virus titer was consistently low compared with that of CMV-Fny-inoculated plants; and the youngest, noninoculated leaves did not contain detectable amounts of this mutant virus strain. In contrast, CMVFny-infected plants had high virus titers in both inoculated and noninoculated leaves of plants expressing chlorosis and mosaic symptoms, with reduced accumulation of the virus in leaves expressing leaf deformation in experiment 1 (Fig. 2A). Similarly, in experiment 2, virus titer was high in inoculated and noninoculated leaves at the chlorosis stage of symptom development but slightly reduced in the mosaic and leaf deformation stages of symptom development (Fig. 2B).

Calwonder stem tissue prints from a single plant per treatment are presented for each of the three cucumber mosaic symptom phases in Figure 3, because results were highly consistent among replicate plants. CMV-Fny $\Delta 2 \mathrm{~b}$ was not detected in any of the immuno-tissue blots regardless of the location of the section along the stem or days post inoculation (Fig. 3A-C, lane 1). In contrast, CMV-Fny accumulated to high levels throughout the stem of each infected plant, with a decrease in immuno-labeling intensity by 25 dpi corresponding to a decline in virus accumulation in leaves (Fig. $3 \mathrm{~A}-\mathrm{C}$, lane 2). No CMV-antibody reaction was detected for stem blots generated from noninfected control plants (Fig. 3A-C, lane 3 ). These data show that, in Calwonder pepper plants, CMV-

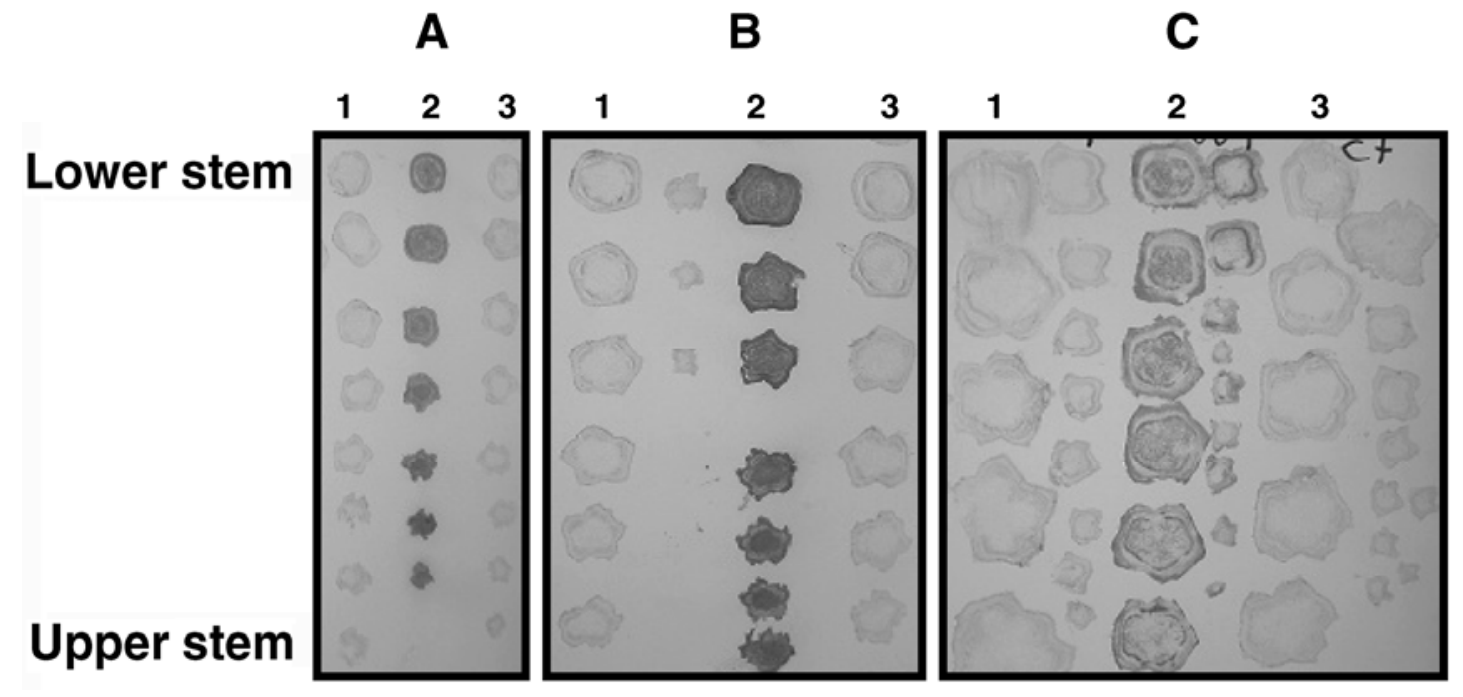

Fig. 3. Immuno-tissue blot analysis of Cucumber mosaic virus Fast New York strain (CMV-Fny, wild-type parent) and CMV-Fny $\Delta 2 \mathrm{~b}$ ( $2 \mathrm{~b}$ mutant of CMV-Fny) accumulation in stem segments from 'Calwonder' pepper plants. Tissue prints were generated from plants inoculated with CMV-Fny $\Delta 2 b$ (lane 1), CMV-Fny (lane 2), and a noninoculated control plant (lane 3) at the time that CMV-Fny infected plants were expressing symptoms of A, chlorosis (7 days post inoculation [dpi]); B, mosaic (12 dpi); and C, leaf deformation (25 dpi). Tissue prints were generated from consecutive internodes starting from the lower part of the stem and moving up the stem. For some treatments (B, lane 1; C, lanes 1,2, and 3), two columns of tissues prints are shown for an individual virus treatment to represent consecutive internodes from the bottom to the top of the stem. A dark stain, as observed in lane 2, indicates a positive CMV coat protein-antibody reaction. 
Fny $\Delta 2 \mathrm{~b}$ was not detected in the stems of infected plants that had detectable virus in inoculated leaves and in some noninoculated leaves, although inconsistently and at a low titer. Furthermore, no symptoms were observed on any of the CMV-Fny $\Delta 2 \mathrm{~b}$-inoculated plants.

Protoplast infection. CMV-Fny $\Delta 2 b$ and CMV-Fny were detected in all protoplast samples; however, CMV-Fny $\Delta 2 \mathrm{~b}$ consistently accumulated to lower levels than that of CMV-Fny for each protoplast treatment (Fig. 4). These virus strains had the same coat protein sequence and reacted similarly to the CMV-specific ELISA kit. Therefore, differences in ELISA absorbance values appeared to be due to differences in virus accumulation, not different reactions of the two CMV strains to the antibody. The repeat of this protoplast experiment showed very similar results (data not shown).

\section{Discussion}

In this study, the results of inoculating tobacco plants with CMV-Fny and CMV-Fny $\Delta 2 \mathrm{~b}$ concurred with those of previous studies, i.e., CMV-Fny $\Delta 2 \mathrm{~b}$ caused asymptomatic infection in tobacco $(29,30)$. The complete lack of detection of CMV-Fny $\Delta 2 b$ in inoculated squash plants was unexpected because this virus has been shown to infect $C$. pepo cultivars (14). Calwonder pepper plants consistently supported CMV-Fny $\Delta 2 \mathrm{~b}$ infection in inoculated leaves but showed limited, inconsistent infection of noninoculated leaves and did not induce local or systemic symptoms of cucumber mosaic. These results appear similar to previous studies, in which CMV was localized to the lower portions of resistant pepper plants $(7,21)$ and in plants thought to express mature plant resistance $(9)$. In those reports, CMV was detected in inoculated leaves and the stems of inoculated plants but infection was limited to lower portions of the plants. In this study, the low titer of CMV-Fny $\Delta 2 b$ detected in some noninoculated leaves of pepper plants above the inoculated leaves but not in the youngest, noninoculated leaves suggests that movement to noninoculated leaves occurred in a cellto-cell manner rather than rapid, phloem-dependent movement to young, developing tissues typically observed with virus infection of bell pepper plants $(2,10,17)$.

Immuno-tissue blot analyses were also performed in this study to determine the extent of CMV-Fny $\Delta 2 \mathrm{~b}$ accumulation in the stems of inoculated pepper plants. Surprisingly, none of the tissue prints contained detectable CMV-Fny $\Delta 2 \mathrm{~b}$, whereas CMV-Fny accumu-

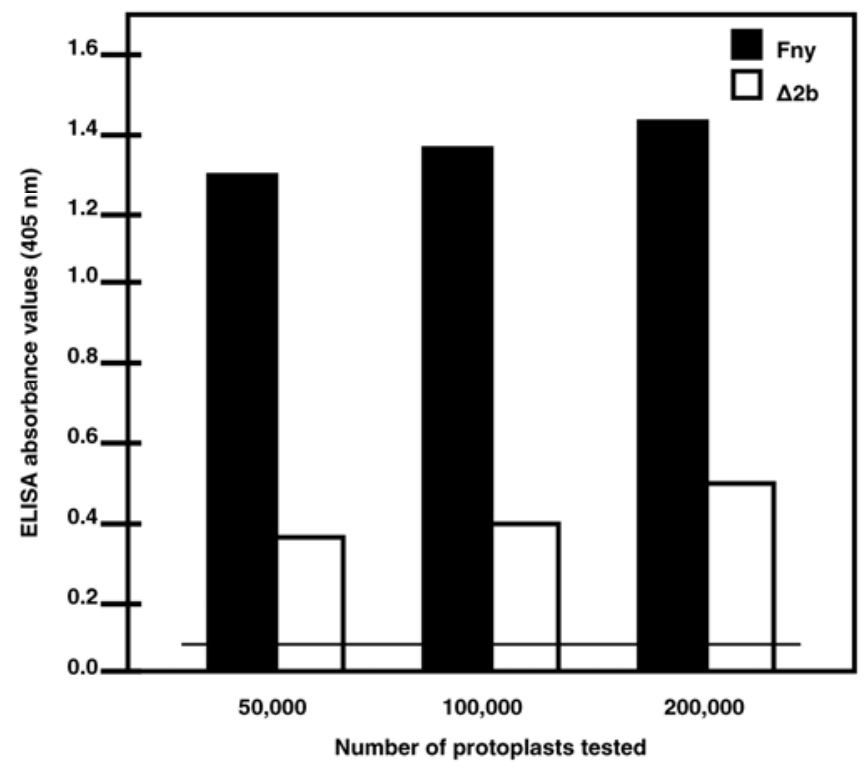

Fig. 4. Accumulation of Cucumber mosaic virus Fast New York strain (CMV-Fny) and CMV-Fny $\Delta 2 \mathrm{~b}$ ( $2 \mathrm{~b}$ mutant) in 'Calwonder' pepper leaf protoplasts. Samples of $50,000,100,000$, and 200,000 protoplasts were collected $24 \mathrm{~h}$ post inoculation for each CMV treatment. Each virus strain was detected by enzyme-linked immunosorbent assay (ELISA). The ELISA threshold was determined from 200,000 bufferinoculated control protoplasts, represented by the horizontal line. lated quickly throughout the stem of each inoculated plant. This raises a concern about sensitivity of the immuno-tissue blot analysis for the mutant strain compared with the ELISA results; however, previous studies showed tissue immunoblots to be capable of detecting virus very soon after inoculation, when virus titers were low $(2,17)$. Assuming that the sensitivity of this method is not a limiting factor, the results further substantiate the highly limited infection of pepper plants by CMV-Fny $\Delta 2 \mathrm{~b}$. CMV $2 \mathrm{~b}$ function typically appears associated with virus movement through the host plant. For example, Sunpapao et al. (30) showed that the 2 b protein of CMV-Pepo was necessary for efficient invasion of the shoot apical meristem and leaf primordia in tobacco plants. In pepper plants in this study, CMV-Fny $\Delta 2 \mathrm{~b}$ did not appear to invade either the shoot apical meristem or leaf primordia but was restricted to the inoculated leaf or showed limited movement to a few older, noninoculated leaves. The CMV-Fny $\Delta 2 \mathrm{~b}$ isolate used in this study had a small portion deleted in the $3^{\prime}$ terminus of the RNA 2 encoded 2a protein (29). We did not determine whether this 2 a protein deletion may have affected infection of pepper plants or interacted with the $2 \mathrm{~b}$ protein deletion, although Ding et al. (5) did not detect a change in infectivity of an isolate of Q-CMV that contained a similar deletion in the $3^{\prime}$ terminus of the 2 a protein.

In previous studies using tobacco protoplasts, accumulation of the wild-type virus, CMV-Fny or CMV-Pepo, was similar to that of the respective $2 \mathrm{~b}$ mutant isolates $(29,30)$. We found that CMVFny $\Delta 2 \mathrm{~b}$ accumulation in pepper protoplasts was consistently lower than that of CMV-Fny, corresponding to the results of whole-plant experiments completed in this study. Qi et al. (25) showed that green fluorescent protein constructs could be silenced in protoplasts, and that co-expression of CMV $2 \mathrm{~b}$ suppressed the silencing. We were able to detect CMV-Fny accumulation in pepper protoplasts $10 \mathrm{~h}$ post inoculation using ELISA (data not shown), which indicated rapid replication and accumulation of this virus at the cellular level. If the reduced pathogenicity of CMV-Fny $\Delta 2 b$ in pepper compared with that of CMV-Fny is due to loss of the genesilencing suppressor $2 b$, reduced accumulation of CMV-Fny $\Delta 2 b$ in pepper protoplasts relative to CMV-Fny may illustrate the efficiency of the silencing mechanism and, for CMV-Fny, the efficiency of a functional $2 \mathrm{~b}$ protein as a silencing suppressor.

\section{Acknowledgments}

We thank J. Carr (Molecular Virology Lab, University of Cambridge, Cambridge, UK) for providing the CMV isolates and the Department of Entomology and Plant Pathology at Auburn University for financial support.

\section{Literature Cited}

1. Anandalakshmi, R., Pruss, G. J., Ge, X., Marathe, R., Mallory, A. C., Smith, T. H., and Vance, V. B. 1998. A viral suppressor of gene silencing in plants. Proc. Natl. Acad. Sci. USA 95:13079-13084.

2. Andrianifahanana, M., Lovins, K., Dute, R., Sikora, E., and Murphy, J. F. 1997. Pathway for phloem-dependent movement of pepper mottle potyvirus in the stem of Capsicum annuum. Phytopathology 87:892-898.

3. Brigneti, G., Voinnet, O., Li, W. X., Ji, L. H., Ding, S. W., and Baulcombe, D. C. 1998. Viral pathogenicity determinants are suppressors of transgene silencing in Nicotiana benthamiana. EMBO J. 17:6739-6746.

4. Diaz-Pendon, J. A., Li, F., Li, W.-X., and Ding, S. W. 2007. Suppression of antiviral silencing by cucumber mosaic virus $2 \mathrm{~b}$ protein in Arabidopsis is associated with drastically reduced accumulation of three classes of viral small interfering RNAs. Plant Cell 19:2053-2063.

5. Ding, S. W., Li, W. X., and Symons, R. H. 1995. A novel naturally occurring hybrid gene encoded by a plant RNA virus facilitates long distance virus movement. EMBO J. 14:5762-5772.

6. Ding, S. W., and Voinnet, O. 2007. Antiviral immunity directed by small RNAs. Cell 130:413-426.

7. Dufour, O., Palloix, A., Gebre-Selassie, K., Pochard, E., and Marchoux, G. 1989. The distribution of cucumber mosaic virus in resistant and susceptible plants of pepper. Can. J. Bot. 67:655-660.

8. Edwardson, J. R., and Christie, R. G. 1997. Viruses infecting peppers and other solanaceous crops Univ. Fla. Agric. Exp. Stn. Inst. Food Agric. Sci. Monogr. I 1:133-139.

9. Garcia-Ruiz, H., and Murphy, J. F. 2001. Age-related resistance in bell pepper to Cucumber mosaic virus. Ann. Appl. Biol. 139:307-317.

10. Guerini, M. N., and Murphy, J. F. 1999. Resistance of Capsicum annuum 'Avelar' to pepper mottle potyvirus and alleviation of this resistance by coinfection with cucumber mosaic cucumovirus are associated with virus 
movement. J. Gen. Virol. 80:2785-2792.

11. Hull, R. 2002. Disease symptoms and host range. Chapter 3 in: Matthews' Plant Virology, 4th ed. Academic Press, New York.

12. Kaper, J. M., and Waterworth, H.E. 1981. Cucumoviruses. Pages 257-232 in: Handbook of Plant Virus Infections and Comparative Diagnosis. E. Kurstak, ed. Elsevier/North-Holland Biomedical Press, Amsterdam.

13. Lewsey, M., Robertson, F. C., Canto, T., Palukaitis, P., and Carr, J. P. 2007. Selective targeting of miRNA-regulated plant development by a viral counter-silencing protein. Plant J. 50:240-252.

14. Lewsey, M., Surette, M., Robertson, F. C., Ziebell, H., Choi, S. H., Ryu, K. H., Canto, T., Palukaitis, P., Payne, T., Walsh, J. A., and Carr, J. P. 2009. The role of the Cucumber mosaic virus $2 \mathrm{~b}$ protein in viral movement and symptom induction. Mol. Plant-Microbe Interact. 22:642-654.

15. Lindbo, J. A., and Dougherty, W. G. 1992. Pathogen-derived resistance to a potyvirus: immune and resistant phenotypes in transgenic tobacco expressing altered forms of a potyvirus coat protein nucleotide sequence. Mol. Plant-Microbe Interact. 5:144-153.

16. Lindbo, J. A., Silva-Rosales, L., Proebsting, W. M., and Dougherty, W. G. 1993. Induction of highly specific antiviral state in transgenic plants: implications for regulation of gene expression and virus resistance. Plant Cell 5:1749-1759.

17. Murphy, J. F. 2002. The relationship between virus source leaf and spread of infection through the stem of Capsicum sp. Arch. Virol. 147:1789-1797.

18. Murphy, J. F. 2003. Cucumber mosaic virus. Pages 29-31 in: Compendium of Pepper Diseases. K. Pernezny, P. Roberts, J. F. Murphy, and N. Goldberg, eds. American Phytopathological Society, St. Paul, MN.

19. Murphy, J. F., and Bowen, K. L. 2006. Synergistic disease in pepper caused by the mixed infection of Cucumber mosaic virus and Pepper mottle virus. Phytopathology 96:240-247.

20. Murphy, J. F., and Kyle, M. M. 1994. Isolation and viral infection of Capsicum leaf protoplasts. Plant Cell Rep. 13:397-400.

21. Nono-Womdim, R., Marchoux, G., Pochard, E., Palloix, A., and GebreSelassie, K. 1991. Resistance of pepper lines to the movement of cucumber mosaic virus. J. Phytopathol. 132:21-32.

22. Palukaitis, P., and Garcia-Arenal, F. 2003. Cucumoviruses. Adv. Virus Res. 62:241-323.

23. Palukaitis, P., Roossinck, M. J., Dietzgen, R. G., and Francki, R. I. B. 1992. Cucumber mosaic virus. Adv. Virus Res. 41:281-347.
24. Palukaitis, P., and Zaitlin, M. 1984. Satellite RNAs of cucumber mosaic virus: characterization of two new satellites. Virology 132:426-435.

25. Qi, Y., Zhong, X., Itaya, A., and Ding, B. 2004. Dissecting RNA silencing in protoplasts uncovers novel effects of viral suppressors on the silencing pathway at the cellular level. Nucleic Acids Res. 32:e179.

26. Ratcliff, F., MacFarlane, S. A., and Baulcombe, D. C. 1999. Gene silencing without DNA: RNA-mediated cross protection between viruses. Plant Cell 11:1207-1215.

27. Ryabov, E. V., Fraser, G., Mayo, M. A., Barker, H., and Taliansky, M. 2001 Umbravirus gene expression helps potato leafroll virus to invade mesophyll tissues and to be transmitted mechanically between plants. Virology 286:363-372.

28. Sambrook, J., Fritsch, E. F., and Maniatis, T. 1989. Molecular Cloning: A Laboratory Manual, Vol. III, 2nd ed. Cold Spring Harbor Laboratory Press, Cold Spring Harbor, NY

29. Soards, A. J., Murphy, A. M., Palukaitis, P., and Carr, J. P. 2002. Virulence and differential local and systemic spread of Cucumber mosaic virus in tobacco are affected by the CMV 2b protein. Mol. Plant-Microbe Interact. 15:647-653

30. Sunpapao, A., Nakai, T., Dong, F., Mochizuki, T., and Ohki, S. T. 2009. The $2 \mathrm{~b}$ protein of cucumber mosaic virus is essential for viral infection of the shoot apical meristem and for efficient invasion of leaf primordia in infected tobacco plants. J. Gen. Virol. 90:3015-3021.

31. Tomlinson, J. A. 1987. Epidemiology and control of virus diseases of vegetables. Ann. Appl. Biol. 110:661-681.

32. Voinnet, O. 2005. Induction and suppression of RNA silencing: insights from viral infections. Nat. Rev. Genet. 6:206-220.

33. Voinnet, O., Pinto, Y. M., and Baulcombe, D. C. 1999. Suppression of gene silencing: a general strategy used by DNA and RNA viruses in plants. Proc. Natl. Acad. Sci. USA 96:14147-14152.

34. Ziebell, H., and Carr, J. P. 2009. Effects of dicer-like endonucleases 2 and 4 on infection of Arabidopsis thaliana by cucumber mosaic virus and a mutant virus lacking the $2 \mathrm{~b}$ counter-defense protein gene. J. Gen. Virol 90:2288-2292.

35. Ziebell, H., Payne, T., Berry, J. O., Walsh, J. A., and Carr, J. P. 2007. A cucumber mosaic virus mutant lacking the $2 \mathrm{~b}$ counter-defence protein gene provides protection against wild-type strains. J. Gen. Virol. $88: 2862-2871$ 